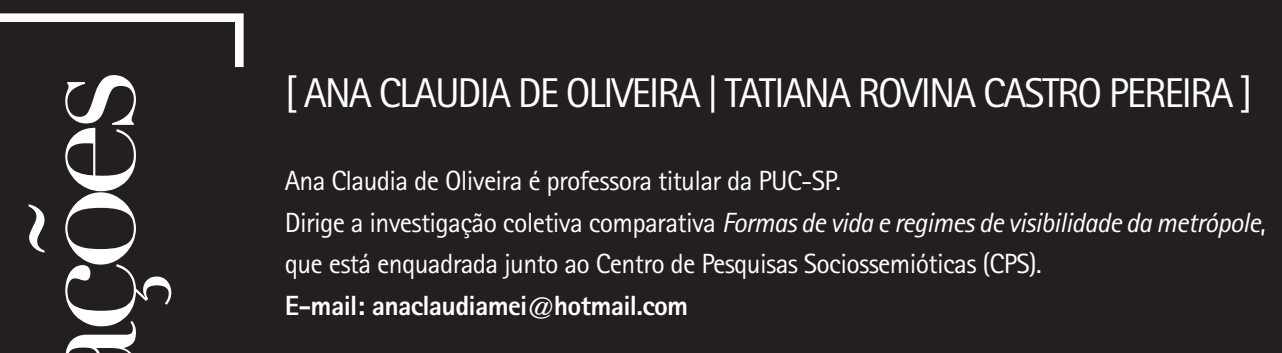

Tatiana Rovina Castro Pereira é mestranda da PUC-SP do PEPG

em Comunicação e Semiótica, pesquisadora do Centro de Pesquisas Sociossemióticas (CPS) e apaixonada por futebol e pela várzea.

E-mail: trcp@yahoo.com

\title{
Nóis é nóis: construções identitárias no futebol de várzea paulistano
}

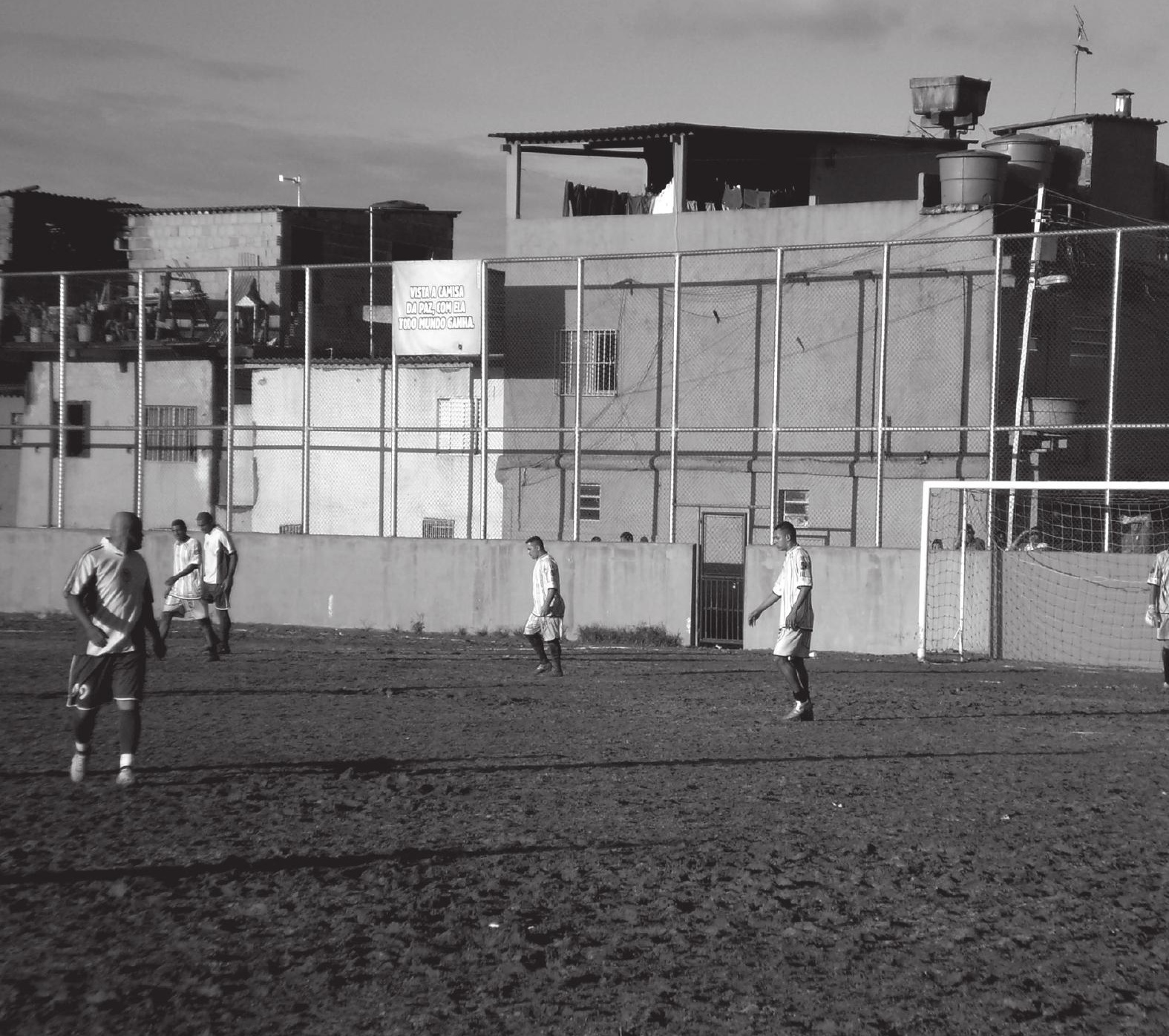




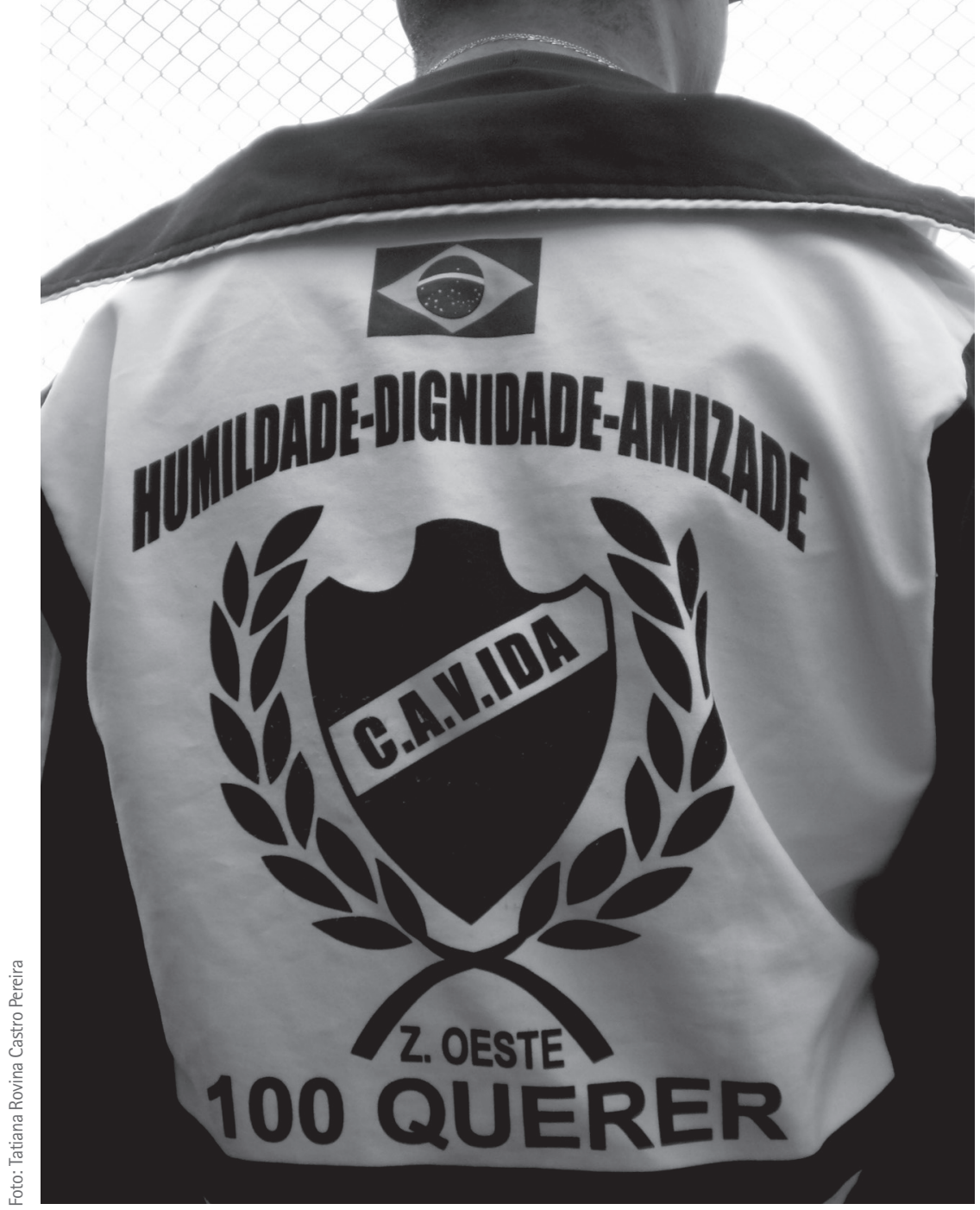

São Paulo, capital. Um sábado ou domingo qualquer, tão importante quanto todos os fins de semana do ano. Nos campos, a bola rola, balança a rede, com clima de decisão. A torcida vibra, xinga, batuca onde nem sempre há arquibancada - $e_{\text {, }}$ às vezes, sequer gramado. Mas essas condições não diminuem o amor pelo futebol, que une "todos juntos em uma mesma emoção". Longe dos estádios e dos times milionários, dos craques espetacularizados e das torcidas organizadas oficiais, o futebol amador faz pulsar as quebradas. No coração das comunidades, espalhadas pelos quatro cantos da metrópole, o grito de gol, que não falta, ecoa, integrando-as.

0 futebol de várzea não recebe cobertura das grandes emissoras de televisão, dos jornais impressos ou dos programas esportivos nas rádios, a não ser em raras ocasiões. Em 2010, o solitário documentário Várzea: a bola rolada na beira do coração ${ }^{1}$, de Akins Kinte, estreou em poucas salas de espaços culturais paulistanos, longe do circuito comercial. No entanto, esse modo de viver o futebol tem uma existência que nos faz querer ressaltá-lo como um acontecimento expressivo das periferias paulistanas, uma forma de vida que evidencia os seus valores e anseios.

Ele praticamente inexiste para as principais empresas do país, ou melhor, é quase invisível, uma vez que não ganha espaço na mídia noticiosa nem apoio de patrocinadores. A busca das mídias e das empresas recai por algum esporte ou jogador carismático com o qual possam se associar, e com esse propósito elas empreendem uma disputa ávida, visando a um bom segmento de mercado a conquistar. No caso dessas manifestações das comunidades paulistanas, uma ou outra marca de bebida (alcoólica, vale ressaltar), nos últimos anos, percebeu a importância que a modalidade esportiva do futebol tem entre as atividades preferidas de lazer das chamadas classes C e D, consumidores em expansão no Brasil, e vinculou sua imagem a essa prática.

Foi assim que, a partir de 1995, a cervejaria Kaiser passou a patrocinar a até então chamada Copa da Cidade - hoje Copa Kaiser ${ }^{2}$, a maior e mais importante competição de futebol amador de São Paulo. Em 2010, são 192 times das zonas Norte, Sul, Leste e Oeste disputando o grupo $A$, e outros 144 das mesmas regiões disputando o grupo $B$ deste campeonato. Um impressionante número de 336 times representando as vilas, os jardins, parques, conjuntos habitacionais, bairros e favelas de toda a cidade.

Comunidades que, separadas pela distância geográfica, mas unidas por um mesmo sentimento, estabelecem laços de afinidade, comunicam-se com ajuda da 


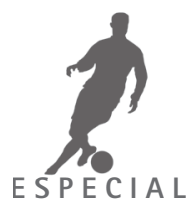

tecnologia (especialmente celulares e internet) e organizam campeonatos paralelos ${ }^{3}$ próprios, mantendo a chama do esporte sempre acesa - e a bola sempre rolando nos pés e nas mentes que se sociabilizam. Os campos, por vezes, são de terra batida, cercados pelas casas, pelos prédios e barracos das quebradas, e a infraestrutura de vestiários, arquibancadas e bancos de reservas e comissão técnica é simples. Mas o que importa, caia chuva ou faça sol, é a sua comunidade que está no jogo e em jogo, e é possivel torcer por ela em pé na beira do campo ou com uma visão especial do alto da laje.

É exatamente esse sentimento de pertencimento e suas formas de socialização, percebidas no esporte como estreita relação de cada time com seu espaço na cidade (trazendo, à superfície, valores, éticas e estéticas específicas de cada um), que faz 0 futebol de várzea tão interessante para um olhar mais atento e emocionante sobre os processos de identidade e identificação nele e por ele representados.

Essa visualidade se dá pelos nomes das equipes, pelas faixas de incentivo e, especialmente, nos uniformes de jogadores e torcedores, um texto criativamente visual, denso de conteúdos, singularizando cada time e seus torcedores.

Não caberia aqui uma relação extensa de citação com os inúmeros e expressivos exemplos sobre os quais poderíamos nos deter. Assim, escolhemos apenas alguns entre os muitos que seriam passiveis de ilustrar esta análise de forma rica e que foram coletados em pesquisas, verdadeiramente, de campo. Porque na invisibilidade da modalidade esportiva, do entretenimento do paulistano, só a prática vivencial do investigador consegue flagrar práticas de vida desta natureza. Por isso mesmo, instiga-se os leitores que façam suas próprias incursões ao bairro ao lado ou àquele campinho no caminho, para experimentar esta paixão, tão nacional e tão localizada, ali onde ela nasce: em todo lugar, mas que, aos olhos midiatizados de uma grande metrópole, é não visto, é lugar nenhum. Diferentemente, a aposta que elaboramos é a de que esses lugares se singularizam por essa forma de vida e de sociabilidade que definem tanto os adeptos da prática esportiva quanto a vida coletiva da periferia.

Os nomes e os dizeres dos gritos e bandeirões de cada time traduzem em linguagem verbal o orgulho de pertencer à comunidade e partilhar dos valores que a permeiam ou, ao menos, como os times gostariam de ser vistos pelas demais, como: Panela Problema F.C. (Jaraguá) ou Tô Envolvido E.C. (Vila Nova Cachoeirinha) da Zona Norte; Consideração F.S. (Campo Grande) ou F.R. Vila Fundão (Vila Fundão) da Zona Sul; Negritude F.C. (Artur Alvim) ou 100 Mizéria A.A. (Parque Guarani) da Zona Leste; e, ainda, Vida Loka E.C. (Vila Brasilândia) ou Nóis é Nóis F.S. (Piqueri) da Zona Oeste. Explicitam-se pontos de vista, proposições críticas de sujeitos que buscam ser vistos pelos atributos que elegem como os seus qualificadores. A consciência de si e do mundo está enunciada no uso particular da língua.

Nas faixas e bandeiras, as éticas se agitam nos textos escritos para serem lidos, apreendidos e respeitados: "Falar de mim é fácil, Difícil é ser eu. Bairro do Limão, é isso mesmo", do Morro da Paz (Bairro do Limão); "Conosco quem quiser, contra nós quem puder", do Nove de Julho F.C. (Casa Verde Alta); e "Humildade - Dignidade - Amizade", do 100 Querer C.A. V.Ida (Vila Ida). Estamos diante de um sujeito que também marca seu lugar pela exposição dessas éticas.

As camisas de jogadores são os elementos mais representativos dessas formas de ser e estar em São Paulo e no esporte - e, afinal, na própria sociedade. Além da numeração e do nome do jogador, do distintivo oficial e nome da equipe, aparecem ainda o nome de algum patrocinador pequeno do bairro, o nome do bairro-sede e a região geográfica em que está na cidade. Pertencer a uma ou outra das zonas e a esta ou aquela quebrada é motivo de orgulho e distinção. Para as camisetas, os casacos e as jaquetas dos torcedores, essa sinalização visual de uma ética e de uma espacialidade no contexto urbano pode ser complementada também com uma imagem que 


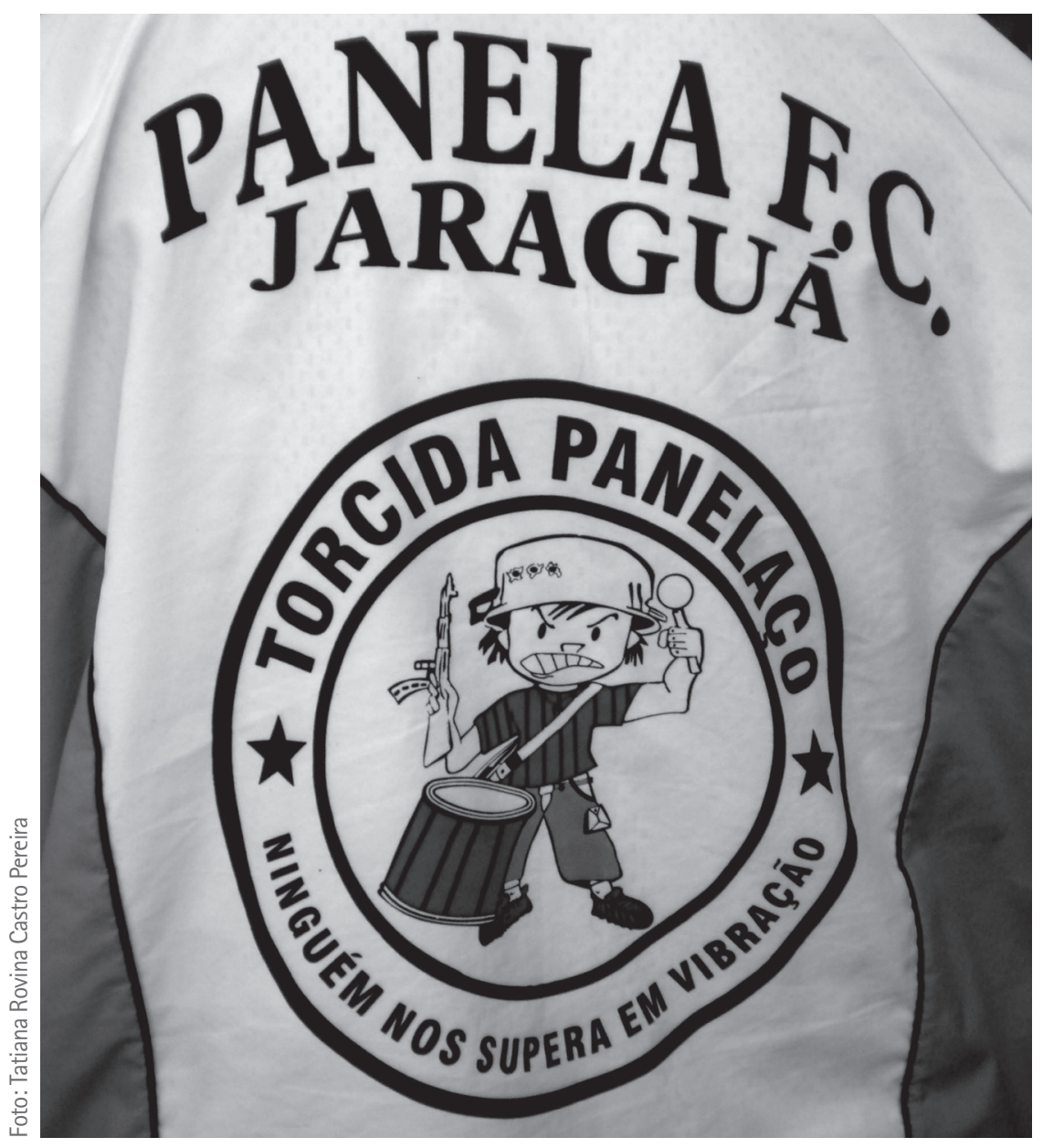

simbolize as crenças dos indivíduos e as verbalizações mais extensas de um "quem somos" que é estabelecido em relação ao que é mesmo plural.

Pareceria impossivel acreditar, para um grande clube vinculado à Federação Paulista de Futebol, que se pudesse ver um uniforme de torcida com dizeres tais quais: "Louco como eu vive pouco, mais (sic) vive do jeito que quer. Jaraguá "somos nóis" (sic), Vila Aurora só que é Família Bartira", como do A.A. Alvorada (Vila Aurora); ou "Agradecemos primeiramente a Deus. A velha guarda que iniciou essa história. Aos que estão privados de sua liberdade. Aos amigos que partiram para nunca mais voltar. Aos adversários que nos fizeram vencer. Aos inimigos que nos ensinaram a lutar. Aos falsos amigos que nos ensinaram a viver. Muito Obrigado!", do já citado 100 Querer C.A. V.Ida; e "Vida Loka. Depois de nóis (sic). É nóis (sic) de novo Jardim Felicidade", de outra família Vida Loka, desta vez do Jardim Felicidade, Zona Sul.

Mas, na várzea, é possível. É possivel ser e pertencer. 0 não lugar em uma metrópole desencaixada de relações declaradas entre os sujeitos de um espaço e o sujeito Outro de outros espaços se refaz em um específico lugar. Aí e agora se investe e se dá a vestir entre arranjos de cores e dizeres, éticas em estéticas que enchem os olhos de sentidos que se manifestam na comunicação entre pares. Pelo menos ali, nos arredores das quatro linhas do gramado, até os extremos de quatro regiões de uma São Paulo imensa, a várzea se veste de si mesma. É a comunidade que entra em jogo. E isso, por si só, já é um grande gol de quem se qualifica porque escolheu fazer as suas jogadas. Como forma de vida cheia de passes, o dentro e o fora do jogo ressoam o gosto do futebol como gosto da gente.

\section{NOTAS}

${ }^{[1]}$ Disponivel em: <http://www.varzeaojogodavida.com.br>. Acesso em: 8 maio 2010.

[2] SIMMM - 0 site do esporte amador. Disponivel em: <http://www.simmm.com.br>. Acesso em: 7 maio 2010

${ }^{[3]}$ Como a Copa da Paz, em sua $3^{\text {a }}$ edição, que acontece no Paraisópolis. Desde a $2^{\mathrm{a}}$ edição, realizada em 2009, tem patrocínio do conhaque Dreher. Mais informações em: <http://futeboldevarzea.dreher.com.br>. 